\title{
Integrated Power Monitoring and Control System
}

\author{
Ogundeji O.A., *Alabi A.A., Babarinde O.O., Adeyeye A.H., Adeleke B.S. \\ Electrical Engineering Department, The Ibarapa Polytechnic, Eruwa, Oyo State, Nigeria
}

\begin{abstract}
This paper presents the design and construction of an Integrated Power Monitoring and Control System which automatically changes over from a low / dead phase to a best / live phase for continued supply of power to load, building or apartment with preset configuration such as: 3 phase supply in (with 1 phase output to load/equipment), inbuilt phase and voltage monitoring sensors, automatic dead phase detection, automatic load transfer to live/active phase, load isolation switch incorporated (The product can serve as a load isolator, totally cutting off mains power from load), user friendly phase selector switches (to manually select any phase of your choice, this is an 'Automatic mode' over-ride function). It can provide real-time information about the following electrical parameter: Voltage, Current, Power Factor, Active Power, Apparent Power, Energy and Frequency. The system is also expected to be able to perform the function of electrical protective devices such as overvoltage, under-voltage, over-current, abnormal frequency and excessive power consumption prevention devices. This device uses only electronic components for the control such that it can be used with smaller generators which do not have this automatic feature on them.
\end{abstract}

Keywords: phase, sensors, load isolator, parameter, power factor, Active Power, Apparent Power, Energy and Frequency.

\section{BACKGROUND TO THE WORK}

A need presently exists for an inexpensive, non-intrusive means of monitoring and controlling power consumption by end users, in an industrial or commercial building, Measurement of peak electrical demand for lighting, heating, cooling and air distribution in a building is essential for both billing and research purposes. Protective devices for sensitive equipment are also as important as the equipment for optimum and reliable performance.

\section{Features and Benefits}

1. It automatically connects your home/office/factory to your Generator whenever public supply fails.

2. It automatically changes from Generator mode to public utility company mode when public power supply is restored.

3. It automatically STARTS your Generator when public power supply fails (No need to go out in the rain or dead of night to start your Gen).

4. It automatically turns OFF your Generator as soon as public utility company energy is restored (No need to go out late in the middle of the night to turn off your Gen)

5. It can be used to interchange load between various types of power sources including WIND TURBINE/MILL, INVERTER, SOLAR POWER UNIT, two or more separate GENERATORS, public utility company etc.It can be used on small or big 'sound proofed' Generators (MIKANO, Marapcoetc), key-start or button-start types

6. Unlike other brands that just switch between Gen and public utility company, our brand of automatic changeover acts as an intelligent Robot that:

(a) It switches to INVERTER mode when public utility company fails, allowing your Inverter to run and operate for expected number of hours $\boldsymbol{B E F \boldsymbol { R } E}$ starting your Generator automatically thereby saving you running costs on Generator fueling and maintenance.

(b)It monitors your Inverter batteries continuously to ensure they do not drain beyond a safe preset but adjustable threshold value typically 10.5 Volts per battery. 
Ogundeji O.A. et al. "Integrated Power Monitoring and Control System"

(c) Immediately Inverter batteries attain the threshold level (at 10.5volts, for instance), Automatic Changeover starts your Generator and switches over to GEN mode, allowing your Inverter batteries to start recharging.

(d) As soon as public utility company supply is restored, the changeover unit changes over to public utility company supply and stops your Generator, saving fuel, while your Inverter batteries continue to recharge.

7. You can turn off the feature ('AUTO MODE') that automatically starts your Gen on power outage and put the unit on 'USER MODE' (also known as 'Manual Mode') so that you as the user could start your Gen only when you need it running.

8. You can choose to ALLOW or DISALLOW public utility company supply (especially in low voltage situations) through the available front switch on the unit which serves as a Public Mains Power Isolator switch.

9. 3-in-1 Model also available for three (3) separate power sources changeover operations such as for premises with Generator 1 (SOURCE 1), Generator 2 (SOURCE 2) and Public Mains (SOURCE 3).

\section{Brief History}

The need for an alternative source of electricity supply to make up for the lapses from the public utility company cannot be over-emphasized in all industries, processing companies, establishments or even our homes where continuous supply of electric power is desirable and needed in countries where supply from public utility companies is not constant. The usual practice is to have a diesel or gasoline generating plant as standby power source so that in the event of a power failure from the utility service provider, the generating plant or generator can be connected and used as an alternative source of power supply to feed the load. With the advent of very sensitive electronic equipment such as computers, control system which requires uninterrupted supply of power, another generation of equipment called uninterruptible power supply (UPS) was developed. The function of the UPS is to serve as an interface between the supply voltage and the load e.g. computer.

The UPS is defined as an independent source of electric power energy which upon failure or outage of nominal source, automatically provides reliable electric power within a specified time to critical devices and equipment whose failure to operate within any short duration would jeopardize an entire operational process.

The reservoir or energy storage form of energy in a UPS is in the form of batteries whose DC voltage output is converted to AC by an inverter when the batteries discharge. The DC voltage passes through a series of operations before transforming into AC.

In modern day UPS models (2000models), switching time of $10 \mathrm{~ms}$ is easily achieved so that the load which the UPS feeds does not notice any power failure during switching because of the extremely fast switching rate.

However, standby power systems (generators) are incapacitated in being automatic due to the following procedures which have to be followed during transfer of load from public utility company supply line to generator line when power fails.

- When there is power failure from public utility company, the power line goes off. An operator then goes to the generator room and switches $\mathrm{ON}$ the generator whose bus bars are not connected to the load.

- The operator then waits for the output voltage of the generator to pick-up and stabilizes and then transfers the load from public utility company bus-bars to Generator bus-bars. It takes between five and ten seconds for a generator to stabilize after it has been switched ON.

- Again, when power is restored by public utility company the operator observes to see if the supply is steady after which he goes to the generator room to transfer the load back to public utility company supply bus-bars and then he switches OFF the generator.

During this procedure, a lot of process or production time is wasted when the operator walks from his office or control room to the generator room; hence there is the need for an extension of the generator ON/OFF switch to the control room. 
If the operator is not very vigilant or even out of the control room when power is restored by public utility company, the generator keeps on running for a longer time which should be resulting in wastage of resources since fuel which is expensive is required to run the generator. Hence there is the need for a sensor which senses the states of input lines from Generator and public utility company supply. Taking note of the fact that the UPS can back up power to the load for a very short period (between 5 and 12minutes), it becomes necessary that the UPS is not allowed to work to its maximum back-up time before the generator is switched on.

With the above reasons which can hinder successful operation of generator and UPS at maximum efficiency, there exists the need for equipment which should take care of all of the above flaws. This equipment is usually installed only on very large automatic standby generator.

It is on this guideline that this project is based on: To construct this device using only electronic components for the control such that it can be used with smaller generators which do not have this automatic feature on them.

As mentioned earlier switches of this type are incorporated only in very large and complicated generators and fitted directly on the control panel of these generators.

\section{Area of Application}

This device is indispensable when quality and quantity of available power from a source to a load is very important.

Residential buildings, telecommunication Systems, data networks, industrial processes.

Health care facilities and critical installations that demand proven electrical power metering and control system.

The system also serves as a versatile load protection device for various categories of user. The System is also as potentially powerful means to reduce household energy consumption by providing convenient low-cost, real-time energy feedback displays feedback to users so they can change their energy using behavior.

\section{Statement of the Problem}

Incessant and unpredictable abnormalities in utility supply in countries with incessant energy supply have made every consumer of electrical energy in such countries to have resulted in the use of different protection mechanisms for their equipment/devices. Also, the electrical energy billing system in the country has also raised a lot of questions; therefore a user-friendly, low-cost utility metering is a good counter-measure to over-billing by public utility company. Though, there are commercially available modules that can be used to implement some of the features of this system. High cost, un-availability and lack of flexibility have made the development of Integrated Power Monitoring and Control System imperative.

\section{Limitation of the Device}

The limitation of this project is that it can only work with single phase generator in line with the parameter stated in chapter four of the project report.

\section{LITERATURE REVIEW AND BACKGROUND OF THE INVENTION}

\section{Automatic Change-Over Switch Overview}

Power instability in developing countries creates a need for automation of electrical power generation or alternative sources of power to back up the utility supply. This automation is required as the rate of power outage becomes predominantly high. Most industrial and commercial processes are dependent on power supply and if the processes of change-over are manual, serious time is not only wasted but also creates device or machine damage from human error during the change-over connections, which could bring massive losses.

The starting of the generator is done by a relay which switches the battery voltage to ignition coil of the generator while the main power relay switches the load to either public supply or generator. The approach used in this work is the modular approach where the overall design was first broken into functional block diagrams, where each block in the diagram represents a section of the circuit that carries out a specific function. 
Ogundeji O.A. et al. "Integrated Power Monitoring and Control System"

A manual change-over switch consists of a manual change-over switch box, switch gear box and cutout fuse or the connector fuse as described by Rocks and Mazur (1993). This change-over switch box separate the source between the generator and public supply, when there is power supply outage from public supply, someone has to go and change the line to generator. Thus when power supply is restored, someone has to put OFF the generator and then change the source line from generator to public supply.

In view of the above manual change-over switch system that involves manpower by using ones energy in starting the generator and switching over from public supply to generator and vice-versa when the supply is restored. The importance attached to cases of operation in hospitals and air ports in order to save life from generator as fast as possible makes it important for the design and construction of an automatic change-over switch which would solve the problem of manpower and the danger likely to be encountered changeover. The electronic control monitors the incoming public supply voltage and detects when the voltage drops below a level that electrical or electronics gadgets can function depending on the utility.

\section{M.S. Ahmed, A.S. Mohammed and O.B. Agusiobo (Jul. 2006)}

The need for an alternative source of electricity supply to make up for the lapses from the public utility company cannot be over-emphasized in all industries, processing companies, establishments or even our homes where continuous supply of electric power is desirable and needed. The usual practice is to have a diesel or gasoline generating plant as standby power source so that in the event of a power failure from the utility service provider (Power Holding Company of Nigeria), the generating plant or generator can be connected and used as an alternative source of power supply to feed the load. With the advent of very sensitive electronic equipment such as computers, control system which requires uninterrupted supply of power, another generation of equipment called uninterruptible power supply (UPS) was developed. The function of the UPS is to serve as an interface between the supply voltage and the load e.g. computer.

The UPS is defined as an independent source of electric power energy which upon failure or outage of nominal source, automatically provides reliable electric power within a specified time to critical devices and equipment whose failure to operate within any short duration would jeopardize an entire operational process.

The reservoir or energy storage form of energy in a UPS is in the form of batteries whose DC voltage output is converted to AC by an inverter when the batteries discharge. The DC voltage passes through a series of operations before transforming into AC.

In modern day UPS models (2000models), switching time of $10 \mathrm{~ms}$ is easily achieved so that the load which the UPS feeds does not notice any power failure during switching because of the extremely fast switching rate.

However, standby power systems (generators) are incapacitated in being automatic due to the following procedures which have to be followed during transfer of load from Public Utility Company supply line to generator line when power fails.

- When there is power failure from Public Utility Company, the power line goes off. An operator then goes to the generator room and switches ON the generator whose bus bars are not connected to the load.

- The operator then waits for the output voltage of the generator to pick-up and stabilizes and then transfers the load from Public Utility Company bus-bars to Generator bus-bars. It takes between five and ten seconds for a generator to stabilize after it has been switched ON.

- Again, when power is restored by Public Utility Company the operator observes to see if the supply is steady after which he goes to the generator room to transfer the load back to Public Utility Company bus-bars and then he switches OFF the generator.

During this procedure, a lot of process or production time is wasted when the operator walks from his office or control room to the generator room; hence there is the need for an extension of the generator ON/OFF switch to the control room.

If the operator is not very vigilant or even out of the control room when power is restored by Public Utility Company, the generator keeps on running for a longer time which should be resulting in wastage of resources since fuel which is expensive is required to run the generator. Hence there is the 
need for a sensor which senses the states of input lines from Generator and Public Utility Company. Taking note of the fact that the UPS can back up power to the load for a very short period (between 5 and 12minutes), it becomes necessary that the UPS is not allowed to work to its maximum back-up time before the generator is switched on.

With the above reasons which can hinder successful operation of generator and UPS at maximum efficiency, there exists the need for equipment which should take care all of the above flaws. This equipment is usually installed only on very large automatic standby generator.

It is on this guideline that this project is based on: To construct this device using only electronic components for the control such that it can be used with smaller generators which do not have this automatic feature on them.

As mentioned earlier switches of this type are incorporated only in very large and complicated generators and fitted directly on the control panel of these generators.

Review

A need presently exists for an inexpensive, non-intrusive means of monitoring and controlling power consumption by end users, in an industrial or commercial building, Measurement of peak electrical demand for lighting, heating, cooling and air distribution in a building is essential for both billing and research purposes. Protective devices for sensitive equipment are also as important as the equipment for optimum and reliable performance.

Automatic Mains Failure module is used in the project with generator monitoring, protection and start facilities. It utilizes advanced surface mount construction techniques to provide a compact yet highly specified module. Operation of the module is via three pushbuttons mounted on the front panel with STOP, MANUAL and AUTO positions. Selection of the 'Auto' mode is confirmed by LED indicator, and monitors the incoming mains supply ( 3 phase or single phase). Should the incoming AC mains supply fall below a configurable pre-set limit (180V default), the generator will be started, and load transferred to the gen-set.

\section{SYSTEM DESIGN AND ANALYSIS}

\section{Design Objectives}

The primary objective of designing this device is to eliminate the need to manually switch our power source and spend our time on more important tasks. The unit senses AC power from various sources, e.g. Inverter / generator / mains power, and automatically switches the output between the various sources accordingly. With prioritized inputs, the most appropriate power source is always selected.

The device primary tasks can be summarized into:

(i) Detection of $\mathrm{AC}$ mains failure.

(ii) Detection of deviation of the main supply voltage, and frequency beyond prescribed limits $(50 \mathrm{~Hz})$

(iii) Detection of restoration of AC mains supply.

(iv) Detection of high/low output voltage and frequency from the utility supply and generator.

(v) Switching of load between alternative power supplies.

Indicators (Pilot Lamps) clearly display when each of the AC power source and AC output power are available. The generator input also comes with voltage sensing and times delays to ensure the generator has warmed up and the voltage is stable before switching to generator power. The generator voltage is continuously monitored and in the unlikely event the generator voltage becomes unstable the device switches to another power source until the generator voltage re-stabilizes.

The block diagram below illustrates major sub-units of Integrated Power Monitoring and Control System, and their inter-connections. This chapter will discuss design of each sub-units the device; and their relationship with one another.

\section{Transformer}

A transformer is a static device that transfers electrical energy from one circuit to another through a shared magnetic field. A changing current in the first circuit (the primary) creates a changing magnetic field; in turn, this magnetic field induces a voltage in the second circuit (the secondary) By 
Ogundeji O.A. et al. "Integrated Power Monitoring and Control System"

adding a load to the secondary circuit, one can make current flow in the transformer, thus transferring energy from one circuit to the other.

The secondary induced voltage Vs is scaled from the primary Vp by a factor ideally equal to the ratio of the number of turns of wire in their respective windings.

By appropriate selection of the numbers of turns, a transformer thus allows an alternating voltage to

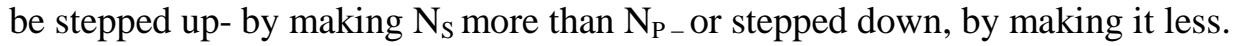

Transformer can be classified based on the way they are used:

- By power level: from a fraction of a volt-ampere (VA) to over a thousand MVA;

- By frequency range: power -, audio- or radio frequency;

- By voltage class: from a few volts to hundreds of kilovolt;

- By cooling type: air cooled, oil cooled, or water cooled;

- By application function: such as power supply, impedance matching, instrumentation, output voltage and current stabilizer or circuit isolation.

- By end purpose: distribution, rectifier, arc furnace, amplifier output;

- By winding turns ratio: step-up, step-down, isolating( near equal ration), variable

\section{Current Transformer}

A current transformer (CT) is used for measurement of electric currents. Current transformers, together with potential transformer (PT), are known as instrument, when current in a circuit is too high to directly apply to measuring instrument, a current transformer produces a reduced current accurately proportional to the current in the circuit, which can be conveniently connected to measuring and recording instrument. A current transformer also isolates the measuring instrument from what may be very high voltage in the monitored circuit. Current transformers are commonly used in metering and protective relays in the electrical power industry.

Like any transformer, a current transformer has a primary winding, a magnetic core, and a secondary winding. The alternating current flowing in the primary produces a magnetic field in the core, which then induces current flow in the secondary winding circuit. A primary objective of current transformer design is to ensure that the primary and secondary circuits are efficiently coupled, so that the secondary current bears an accurate relationship to the primary current.

The most common design of current transformer consists of a length of wire wrapped many times around a silicon steel ring passed over the circuit being measured. The CT's Primary circuit therefore consists of a single turn of conductor, with a secondary of many hundreds of turns. The primary winding may be a permanent part of the current transformer, with a heavy copper bar to carry current through the magnetic core. Window-type current transformers are also common, which can have circuit cables run through the middle of an opening in the core to provide a single-turn primary winding. When conductors passing through a CT are not centered in the circular (or oval) opening, slight inaccuracies may occur.

Shapes and size can vary depending on the end user or switchgear manufacture. Typical examples of low voltage single ratio metering current transformer are either ring type or plastic mounted case. Higher-voltage current transformer is mounted on porcelain bushing to insulate them from ground. Some CT configurations slip around the bushing of a high-voltage transformer or circuit breaker, which automatically centers the conductor inside the CT window. The primary circuit is largely unaffected by the insertion of the CT. the rated secondary current is commonly standardized at 1 or 5A. For example, a 4000:5 CT would provide an output current of 5A when the primary was passing 4000A. The secondary winding can be single ratio or multi-ratio, with five taps being common for multi ratio CTs. The load, or burden, of the CT should be of low resistance. If the voltage time integral area is higher than the core's design rating, the core goes into saturation towards the end of each cycle, distorting the waveform and affecting accuracy.

\section{- Application of Current Transformer}

Current transformers are used extensively for measuring current and monitoring the operation of the power grid. The CT is typically described by its current ratio from primary to secondary. Often, multiple CTs are installed as a "stack" for various uses. For example, protection devices and revenue 
Ogundeji O.A. et al. "Integrated Power Monitoring and Control System"

metering may use separate CTs; stacking them provides severability while consolidating the high voltage interface. Similarly, potential transformers such as the CVT are used for measuring voltage and monitoring the operation of the power grid.

\section{- Safety Precautions}

Care must be taken that the secondary of a current transformer is not disconnected from its load while current is flowing in the primary, as the transformer secondary will attempt to continue driving current across the effectively infinite impedance. This will produce a high voltage across the open secondary (into the range of several kilovolts in some case), which may cause arcing. The high voltage produced will compromise operator and equipment safety and permanently affect the accuracy of the transformer.

The accuracy of a CT is directly related to a number of factors including: Burden, Burden class / Saturation class, Rating Factors, Load, External electromagnetic fields, Temperature and physical configuration. The selected tap, for multi-ratio CT's Phase difference is important when power measurements are involved, i.e. when using wattmeter, kilowatt- hour meters, Var meter and Power Factor meters.

\section{- Burden}

The load, or burden, in a CT metering circuit is the (largely resistive) impedance presented to its secondary windings, Items that contribute to the burden of a current measurement circuit are switchblocks, meters and intermediate conductors. The most common source of excess burden in a current measurement circuit is the conductor between the meter and the CT. Often, substation meters are located significant distances from the meter cabinets and the excessive length of small gauge conductor creates a large resistance. This problem can be solved by using CT with 1A secondary which will produce less voltage drop between a CT and its metering devices (used for remote measurement).

\section{Power Supply}

To ensure proper function, use minimum power supply cable of $1.5 \mathrm{~mm}^{2}$.Maximum continuous DC power supply voltage is $36 \mathrm{~V}$ DC. Maximum allowable power supply voltageis 39VDC. The InteliLite's power supply terminals are protected against large pulse power disturbances. When there is a potential risk of the controller being subjected to conditions outside itscapabilities, an outside protection devise should be used.

The InteliLite controller should be grounded properly in order to protect against lighting strikes.

The maximum allowable current through the controller's negative terminal is $4 \mathrm{~A}$ (this is dependent onbinary output load).

For the connections with 12VDC power supply, the InteliLiteincludes internal capacitors that allow the controller to continue operation during cranking if the battery voltage dip occurs. If the voltage before dip is $10 \mathrm{~V}$, after $100 \mathrm{~ms}$ the voltage recovers to $7 \mathrm{~V}$, the controller continues operating. During this voltage dip the controller screen backlight can turn off and on but the controller keeps operating. It is possible to further support the controller by connecting the external capacitor and separating diode:

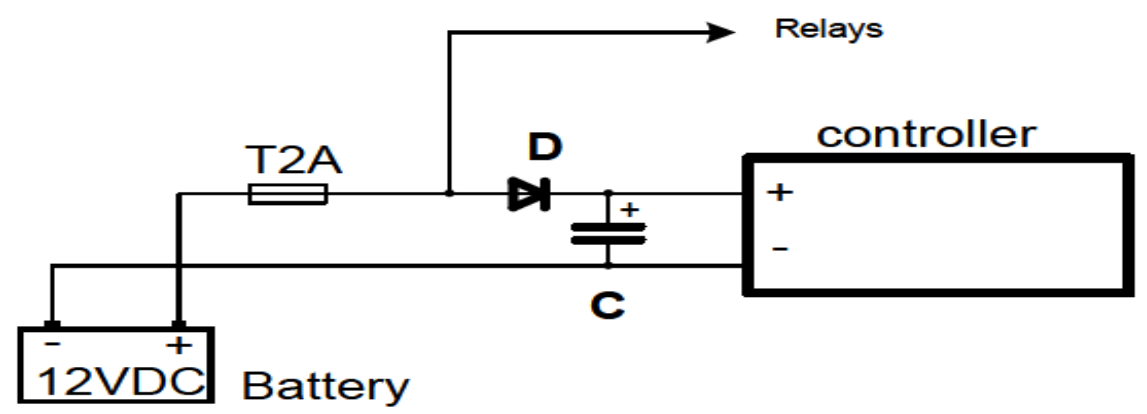

Fig1. Power Supply

The capacitor size depends on required time. It shall be approximately thousands of microfarads.

The capacitor size should be 5000 microfarad to withstand $150 \mathrm{~ms}$ voltage dip under following conditions: Voltage before dip is $12 \mathrm{~V}$, after $150 \mathrm{~ms}$ the voltage recovers to minimum allowed voltage, i.e. $8 \mathrm{~V}$. 


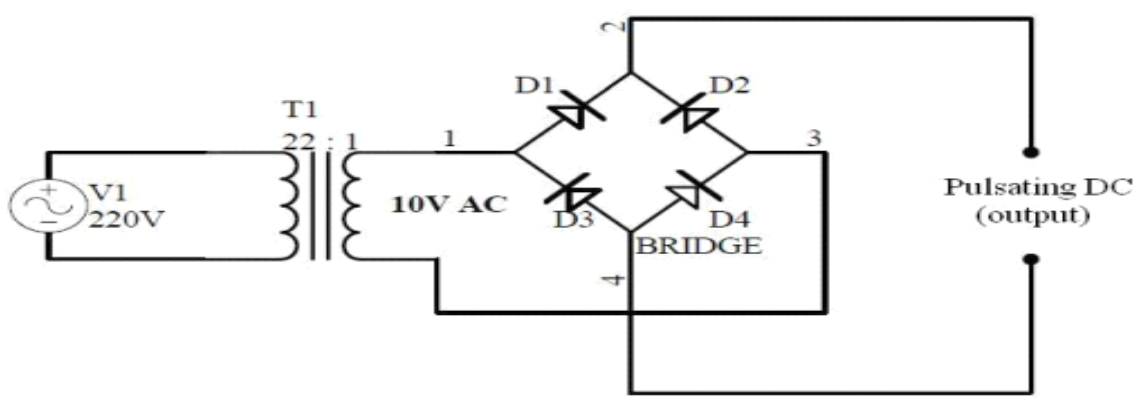

Fig2. Full Wave Rectifier

\section{Frequency Detecting Circuit}

This part of the control circuit is used for translation of transformer output voltage $\left(15 \mathrm{~V}_{\text {rms }}\right)$ into level that is suitable for interpretation by the microcontroller. It mainly consists of zero-crossing detector and voltage translator circuit. The ac voltage from transformers outputs are half-wave rectified and fed into the non-inverting input of the comparator through resistors $R_{16}$ and $R_{17}$. The inverting inputs of the comparators are connected to reference voltage of about 0.7 volts (obtained from Resistor $R_{4}$ and Diode $\mathrm{D}_{5}$, Resistor $\mathrm{R}_{5}$ and Diode $\mathrm{D}_{6}$ pairs). As the output goes from zero to $\mathrm{V}_{\text {peak }}$ in the positive half-cycle of the mains, the moment the ac voltage is higher than $0.7 \mathrm{volts}$, the corresponding comparator output transits from $0 \mathrm{v}$ to $5 \mathrm{v}$. This transition from low to high (Leading edge) will be interpreted by the microcontroller. Such transitions will be counted by the microcontroller and the total number of transitions in a second is the frequency in hertz of the mains Igenerator supply.

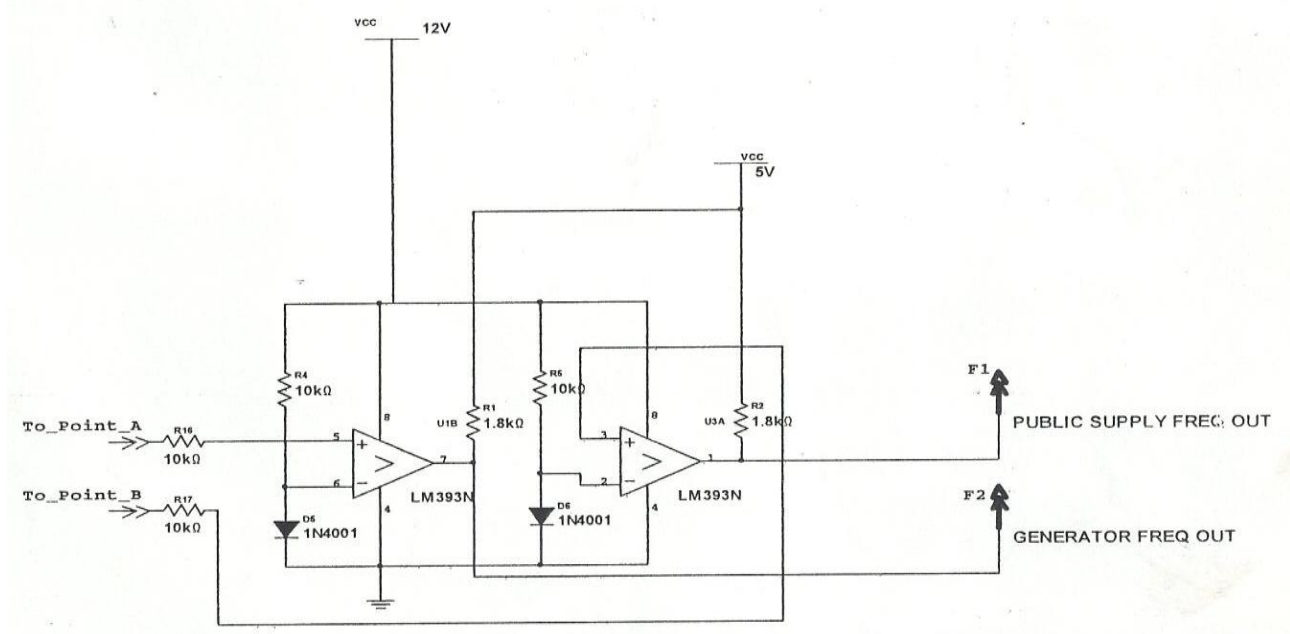

Figure3. Circuit Diagram of the Zero-crossing Detector\{InteliLiteNT\}

\section{Voltage Sampler Circuit}

The voltage sample circuit is a resistive potential diving network.

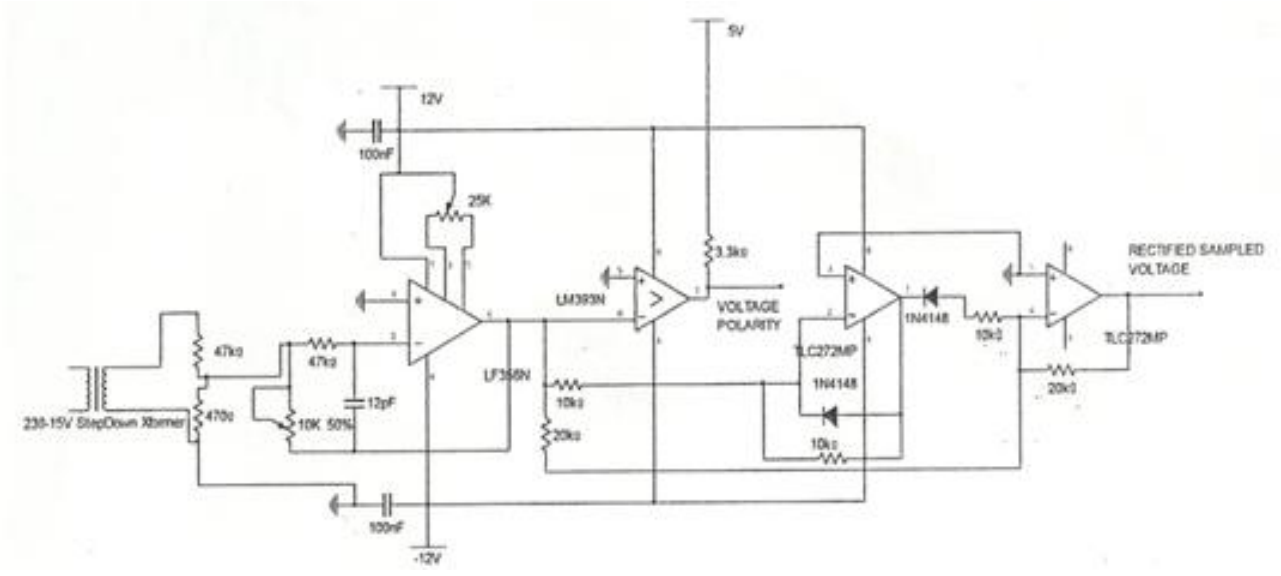

Figure4. Circuit Diagram of the voltage Sampler\{InteliLiteNT\} 
The resistors $\mathrm{R}_{11} \cdot \mathrm{R}_{12}, \mathrm{R}_{13}$ and $\mathrm{R}_{14}$ form the diving networks. They are used to attenuate the output voltage of the transformers to levels that can safely be measured by the microcontroller ADC. Zener diodes $\mathrm{D}_{11}$ and $\mathrm{D}_{13}$ are used to clamp the attenuated voltage to 5.0Volts to prevent the input voltage into the microcontroller from exceeding 5 Volts.

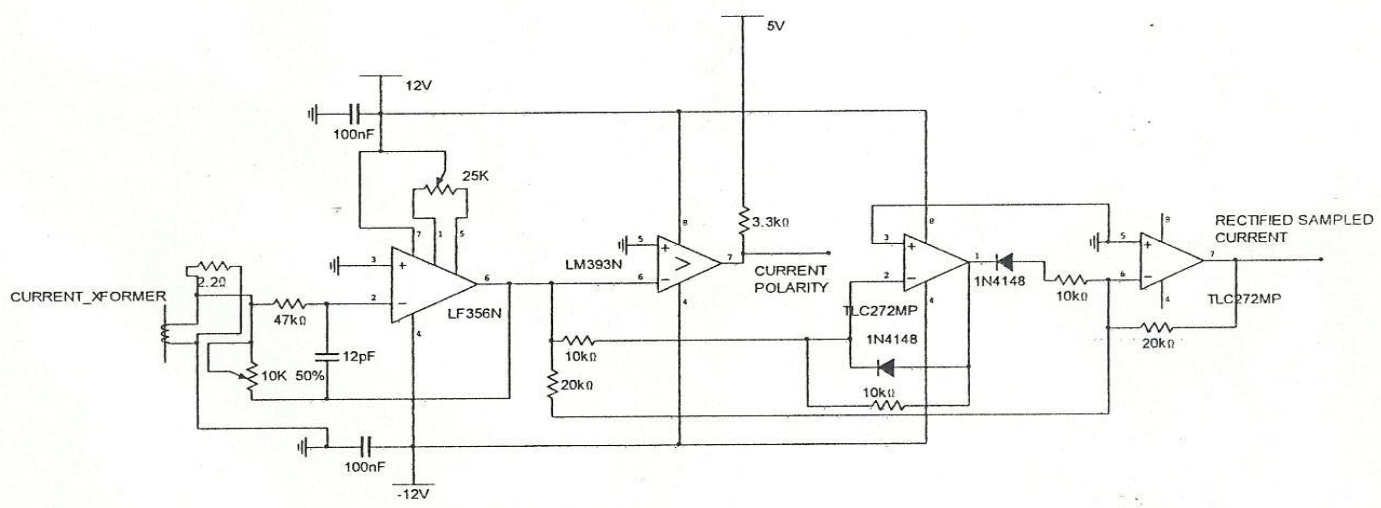

Figure5. Circuit Diagram of the current Sampling Circuit\{InteliLiteNT\}

\section{Hardware Overview}

AMF25 is an Automatic Mains Failure module with generator monitoring, protection and start facilities. It utilizes advanced surface mount construction techniques to provide a compact yet highly specified module. Operation of the module is via three pushbuttons mounted on the front panel with STOP, MANUAL and AUTO positions. Selection of the 'Auto' mode is confirmed by LED indicator, and monitors the incoming mains supply ( 3 phase or single phase). Should the incoming AC mains supply fall below a configurable preset limit (180V default), the generator will be started, and load transferred to the gen-set. When the AC mains supply returns to within limits, the module will wait for a configurable, pre-set stabilization period, and then transfer load back to the mains.

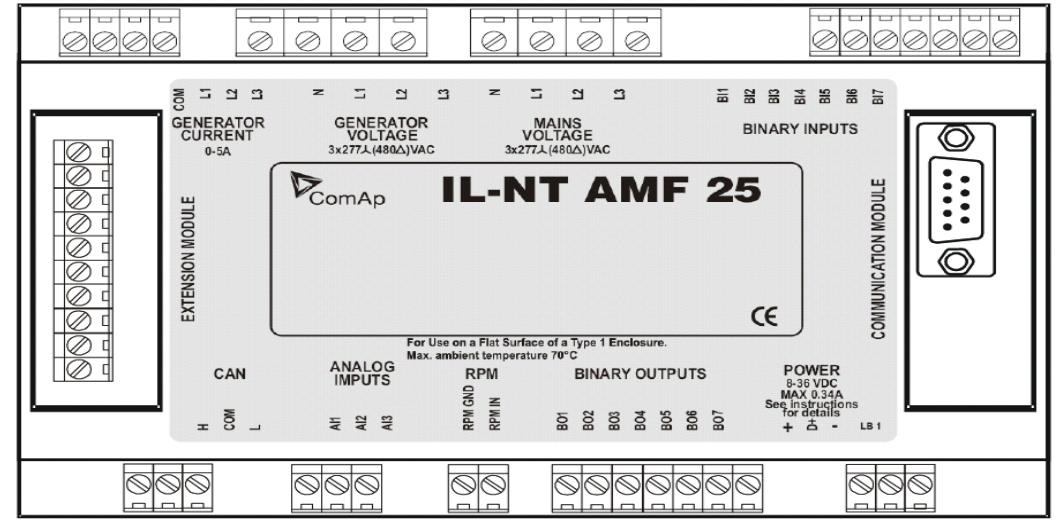

Figure6. Hardware Overview

\section{Firmware Overview}

The main loop is responsible for monitoring the mains supplies' rms voltage and frequency; and maintaining the visual display shown on the LCD.

It measures the utility supply voltage, $\mathrm{V}_{\mathrm{PHCN}}$. If $\mathrm{V}_{\mathrm{PHCN}}$ is greater than $260 \mathrm{Volts}$ or less than $200 \mathrm{Volts}$ it goes to generator control/monitoring subroutine (GT). Also, the frequency of utility supply is monitored and value that deviates outside 45 Hertz $<\mathrm{F}_{\mathrm{PHCN}}<55 \mathrm{Hertz}$ automatically transfers the control to generator control/monitoring subroutine (GT). In the generator control/monitoring subroutine (GT) subroutine, if the generator is not running, the control algorithm checks if the generator has been previously faulty, if generator is faulty, it starts the alarm, and display "Faulty Generator" on the LCD and continue looping on that until the system is reset by the user after the generator fault is supposedly cleared.

If the generator has not been started, the system starts it (provided it is an automatic generator) transfers the control to generator control/monitoring subroutine (GT). 
Ogundeji O.A. et al. "Integrated Power Monitoring and Control System"

In the generator control/monitoring subroutine, the logarithm checks if the generator is running (by monitoring the generator output voltage and frequency). Supposing the generator is not running and it has been started, the system raises alarm and stops re-starting of the generator. If the generator is running, the voltage and frequency output of the generator is then monitored for any deviation in expected values. It measures the generator supply voltage. $\mathrm{V}_{\mathrm{GEN}}$. If $\mathrm{V}_{\mathrm{GEN}}$ is greater than $270 \mathrm{Volts}$ or less 200 Volts it goes to generator fault mode. Also, the frequency of generator supply is monitored and value that deviates outside $40 \mathrm{Hertz}<\mathrm{F}_{\mathrm{GEN}}<60 \mathrm{Hertz}$ (after more than 10 minutes of starting the generator) automatically stops the generator, raise alarm and displays 'FAULT' on the LCD.

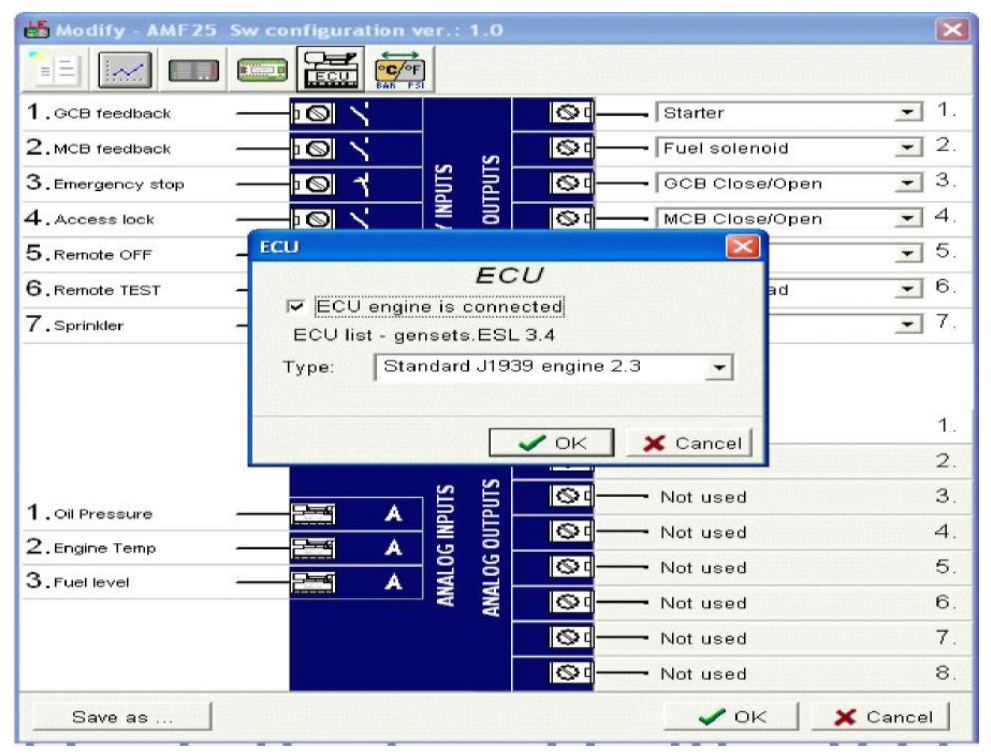

Fig7. Firmware

\section{Interrupts Handlers}

The tasks of interrupts handlers can be sub-divided into three parts: Analog-to-Digital Conversion (ADC) Management, Data Pre-processing, and External Events managements. The ADC measures the sampled Voltage and Current. Voltages values are updated every time analog-to-digital conversion is complete. The controller Timer0 is used for general timing. External interrupts E0 and E1 are configured for falling edge trigger, to monitor and count the zero crossing for every cycle of the generator and mains supplies respectively. The algorithm also performs software filtering to prevent line and circuit noise from being mistakenly interpreted as actual zero crossing points.

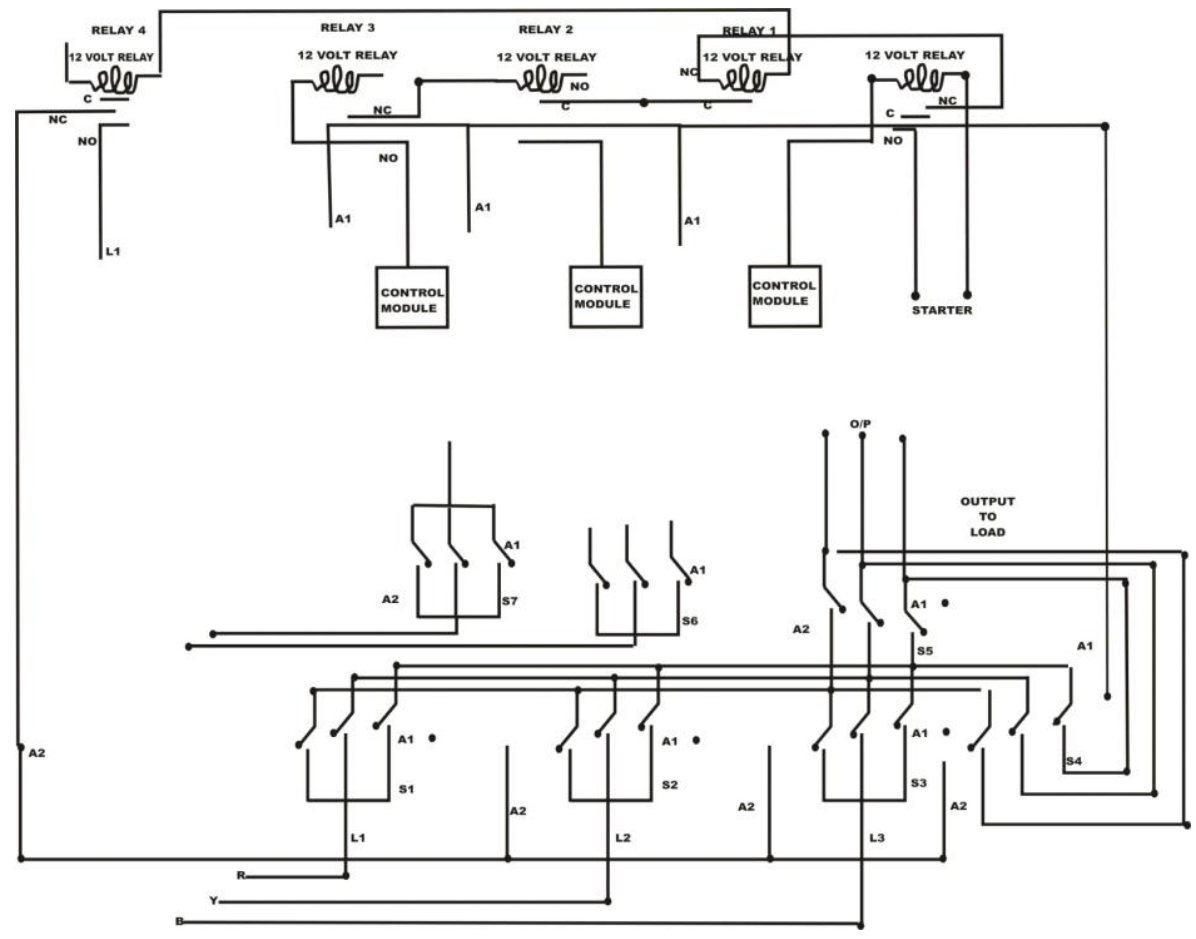

Fig8. Circuit Diagram 


\section{Design and Calculation for Timing Circuit}

The delay circuit used in the construction is a transistor base in which it is based on the principle of charging rate of a capacitor with a constant current. The operation is such that the delay is the required time for the capacitor to charge up before discharging.

Using the formula

Transistor type $=2$ SA733 PNP

The value for $\beta$ for $2 \mathrm{SA} 733$ is $40-600$.

From figure $2.9 \mathrm{~b}$ the circuit is used to obtain a 25 seconds delay at the input stage of PHCN.

To obtain $I_{B}$

Adding the resistor combination in series

\section{Designs for Generator Timer}

The pulse which trigger the generator timer takes its power from a 24volts battery which is usually charged when there is power supply at the Public Utility Company supply line but its output is open circuit by a relay also controlled by the 24 volt battery so that it serves as a backup power for the system and is connected to the kick starter to switch ON the generator and transfer load from Public Utility Company supply contactors to generator contactors when there is no power in either Public Utility Company supply or generator lines.

The voltage drop as the condenser discharges through the timer must not exceed 4.0 volts until the entire switching process is complete for the generator to switch on transfer load from Public Utility Company supply to generator.

The time taken for generator to come ON, and stabilize after which load is transferred to it is 5 seconds according to design specification.

Calculation for timer to startup the generator:

We can make use of the formula

Where $\mathrm{T}$ is the time in seconds, $\mathrm{R}$ is the resistor in ohms, and $\mathrm{C}$ is the capacitor in Farads.

From the above formula,

$\mathrm{T}=5$ seconds

If we choose $\mathrm{C}$ to be $2200 \mu \mathrm{F}$

$\mathrm{C}=2200 \mu \mathrm{F}$

Then $\mathrm{R}$ will be:

$\mathrm{R}=2272 \Omega$

$\mathrm{R}=2.3 \mathrm{~K} \Omega$

Hence I choose a $2.5 \mathrm{k} \Omega$ resistor so that the $\mathrm{T}$ constant is increased to give room for some allowance.

Calculation for timer to stop the generator:

The generate delay timer needed for the generator to be running for a period of 5 mintes ( 300 seconds) after Public Utility Company supply must have been restored. This period is meant to monitor the public supply if it is stable before switching OFF the generator.

From the figure $2.5(\mathrm{~b})$

$\mathrm{T}=1.1 \mathrm{RC}$

Where $\mathrm{T}$ is the time in seconds, $\mathrm{R}$ is the resistor in ohms, and $\mathrm{C}$ is the capacitor in Farads.

From the above formula,

$\mathrm{T}=300$ seconds

$\mathrm{R}=4.7 \mathrm{~m} \Omega$ (choosing)

$300=1.1 \times 4.7 \times 10^{-6} \mathrm{C}$

But this value for the capacitor was not a standard value so a standard capacitor of value of $47 \mu \mathrm{F}$ was used. 


\section{Inter-Relation of Sub-Units}

There are 2 power sources within the modular system (ACS). One of them on the generators side and the other one on the Public Utility Company supply side.

There are also 3 timing circuits. One for switching the generator ON and subsequently transferring load to the generators contactors five seconds after power failure or five seconds after the generator has come ON. The timer takes its power ( $\mathrm{Vcc}$ ) from a condenser which is energized by the power source which the PHCN lines supply. The second timer is used for timing power when restored back by PHCN. In this stage the time is at two points a 25 seconds delay at the input of PHCN to monitor the supply and also to inform the generator that PHCN is back. While the other 5seconds is to allow the generator contactors to transfers the load over to the PHCN contactors. The third timer is used to monitor the stability of the restored power supply by PHCN for a period of about 300 seconds before switching OFF the generator if no interruption of power failure occurs again during the time frame.

The contactor and relays serve as switches for the generators ON/OFF switch as well as for transfer of load between PHCN and generator lines. The major differences between the two is that the relay is been operated on a 24 volt d.c while the contactors operated on a 220 volt a.c

\section{Relay}

A relay is an electrical switch that opens and closes under the control of another electrical circuit. In the original form, the switch is operated by an electromagnet to open or close one or many sets of contacts. It was invented by Joseph Henry in 1835. Because a relay is able to control an output circuit of higher power than the input circuit, it can be considered, in a broad sense, to be a form of an electrical amplifier.

\section{- Operation}

When a current flows through the coil, the resulting magnetic field attracts an armature that is mechanically linked to a moving contact. The movement either makes or breaks a connection with a fixed contact. When the current to the coil is switched off, the armature is returned by a force approximately half as strong as the magnetic force to its relaxed position. Usually this is a spring, but gravity is also used commonly in industrial motor starters. Most relays are manufactured to operate quickly. In a low voltage application, this is to reduce noise. In a high voltage or high current application, this is to reduce arcing.

If the coil is energized with DC, a diode is frequently installed across the coil, to dissipate the energy from the collapsing magnetic field at deactivation, which would otherwise generate a spike of voltage and might cause damage to circuit components.

\section{- Types of Relay}

Latching relay, Reed relay, Mercury-wetted relay, a mercury-wetted reed relay, Polarized relay, Machine tool Relay, Solid state contactor relay, Buchholz relay, Forced-guided contacts relay, Solidstate relay, Overload protection relay, protective relay and over current relay.

\section{Contactor}

A contactor is a very heavy-duty relay used for switching electric motors and lighting loads. With high current, the contacts are made with pure silver. The unavoidable arcing causes the contacts to oxides and sliver oxide is still a good conductor. Such devices are often used for motor starters. A motor starter is a contactor with overload protection devices attached. The overload sensing devices are a form of heat operated relay where a coil heats a bi-metal strip, or where a solder pot melts, releasing a spring to operate auxiliary contacts. Theses auxiliary contacts are in series with the coil. If the overload senses excess current in the load, the coil is de-energized. Contactor relays can be extremely loud to operate, making them unfit for use where noise is a chief concern. A contactor is composed of three different systems. The contact system is the current carrying part of the contactor. This includes Power Contacts, Auxiliary Contacts, and Contact Springs. The electromagnet system provides the driving force to close the contacts. The enclosure system is a frame housing the contact and the electromagnet. Enclosures are made of insulating materials like Bakelite, Nylon 6, and thermosetting plastics to protect and insulate the contacts and to provide some measure of protection against personnel touching the contacts. Open-frame contactors may have a further enclosure to protect against dust, oil, explosion hazards and weather. 
Ogundeji O.A. et al. "Integrated Power Monitoring and Control System"

Contactors used for starting electric motors are commonly fitted with overload protection to prevent damage to their loads. When an overload is detected the contactor is tripped, removing power downstream from the contactor.

Some contactors are motor driven rather than relay driven and high voltage contactors (greater than 100 volts) often have arc suppression systems fitted (such as a vacuum or an inert gas surrounding the contacts).

Contactors are often used to provide central control of large lightings, such as an office building or retail building. To reduce power consumption in the contactors coils, two oil latching contactors are used. One coil, momentarily energized, closes the power circuit contacts; the second opens the contacts.

A basic contactor will have a coil input (which may be driven by either an AC or DC supply depending on the contactor design) and generally a minimum of two poles which are controlled.

\section{- Ratings}

Contactors are rated by designed load current per contact (pole), maximum fault withstand current, duty cycle, voltage, and coil voltage.80A Contactor is used for the purpose of this project.

\section{- Applications}

Some of common applications of relays are:

- to control a high-voltage circuit with a low-voltage signal,

- to control a high-current circuit with a low-current signal, to detect and isolate faults on transmission and distribution lines by opening and closing circuit breakers (protection relays),

- to isolate the controlling circuit from the controlled circuit when the two are at different potentials,

- to perform logic functions,

- to perform timer delay functions.

\section{Battery}

An electric battery is a device consisting of one or more electrochemical cells that convert stored chemical energy into electrical energy. Each cell contains a positive terminal, or cathode, and a negative terminal, or anode. Electrolytes allow ions to move between the electrodes and terminals, which allows current to flow out of the battery to perform work.

Batteries come in many shapes and sizes, from miniature cells used to power hearing aids and wristwatches to battery banks the size of rooms that provide standby power for telephone exchanges and computer data centers.

Batteries have much lower specific energy (energy per unit mass) than common fuels such as gasoline. This is somewhat mitigated by the fact that batteries deliver their energy as electricity (which can be converted efficiently to mechanical work), whereas using fuels in engines entails a low efficiency of conversion to work.

The type of battery used in this project is $12 \mathrm{~V} 6.5 \mathrm{Ah}$ rechargeable (secondary) battery to power the Auto Mains Failure (AMF) and the battery can serve this purpose for Ten (10) good hours according to the specifications.

\section{Methodology}

The operation of the power unit was well organized and coordinated for an efficient performance. The operational process is outlined below:

(i) The power circuit is not active when there is A.C. mains supply.

(ii) Its response to A.C. mains supply power failure is by switching on the starting mechanism of the generator.

(iii)There is a delay in the loading of the generator so as to attain stability for a while. After the said delay, the generator is loaded. 
Ogundeji O.A. et al. "Integrated Power Monitoring and Control System"

(iv)Power supply from the generator is interchanged the moment the A.C. mains are restored. Immediately after this the generator is switched off.

The circuit contains some integrated circuits (IC) more especially the CMOS (complimentary metallic oxide silicon) type. The CMOS consumes less power from the battery. That is why it was incorporated into the circuit. The circuit also consists of relays that provide external switching. These devices are quite robust for efficiency and reliability.

\section{TESTING AND RESULT ANALYSIS}

\section{Construction and Testing}

This chapter describes how the circuit was connected together and how this circuit was installed and tested for its performance. It also describes the response of the system when installed on a generating plant as a test run to see its on-line performance.

\section{Construction}

The circuit was first of all simulating using protues 8 during the experimental sage and the various parts built, beginning from the power source. Various values of components were tried at this stage and the components which combined to give the best result were selected for use. At this stage variable resistors were mainly used so that values can be varied as the system response to these variation observed.

Calculations relating to these variations were done and the best value for design purposes as well as practicability purposes were recorded and designed for while moving to the next stage of the design. A digital meter was used to measure voltage and current at different points in the circuit and light emitting devices were also used in many points to indicate response as well. All resistors which were finally selected to be used were $0.25 \mathrm{~W}$ rating. A block diagram showing all the components used and their inter-connections is shown in fig 9

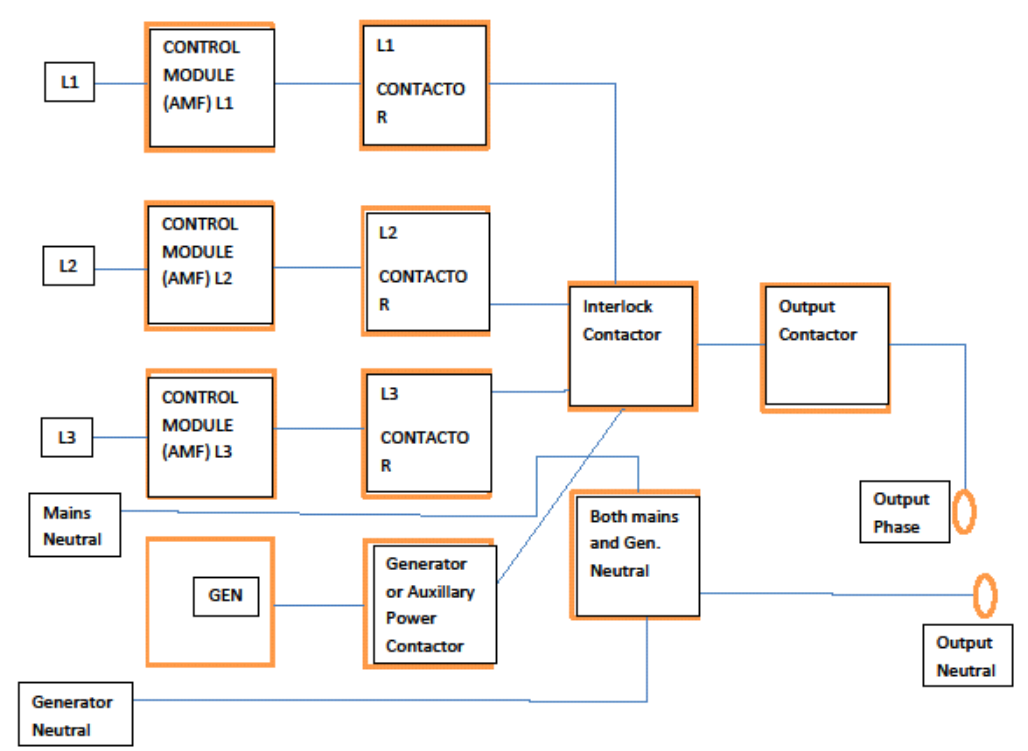

Fig9. Block Diagram of the System

Testing

The PHCN lines red, yellow, blue and neutral were connected to the labeled contractor through a switch gear, while generator lines were connected to the labeled contactor.

Also three lamps were used as indicators $\mathrm{L}_{1}$ (red), $\mathrm{L}_{2}$ (yellow), $\mathrm{L}_{3}$ (blue). The 24 volt battery for the generator severs as the backup for the system. All connection was made to the appropriate point as shown in figure 4.1 block diagram of the project and the following conditions were tested.

\section{Conditions of Operation}


Ogundeji O.A. et al. "Integrated Power Monitoring and Control System"

ii PHCN CONTACTOR OFF GEN CONTACTOR OFF

iii GEN CONTACTOR ON PHCN CONTACTOR OFF

iv

GEN CONTACTOR ON
[2]

\section{PHCN CONTACTOR OFF}

However, after the completion of the connections condition two [ii] was the first to occur so an override was made by switching ON PHCN from the switch gear, the relay switches ON after about 5 seconds thereby transferring the load to the PHCN contactor. The system was later restored back to condition two [ii] by switching OFF the switch gear. It was observed that the generator started running and after a period of about 7 seconds load was transfer to the generator contactor. While the generating set was still running the switch gear was switch ON to test for condition [iv] and it was observed that this condition lasted for 30 seconds. The first 25 seconds was used to monitor the stability of PHCN supply why the order 5 seconds was the period were the change-over from generator to PHCN occurs.

From the stimulated tests carried out in the laboratories it was confirmed that the system worked according to expectation and specification.

\section{Close-On / Close-Off}

The set point influences the behavior of the output MCB CLOSE/OPEN

CLOSE-ON: When the output MCB CLOSE/OPEN is closed - MCB should be closed.

CLOSE-OFF: When the output MCB CLOSE/OPEN is closed - MCB should be opened. The diagram of figure 4.2 illustrate the condition of CLOSE-ON and CLOSE-OF

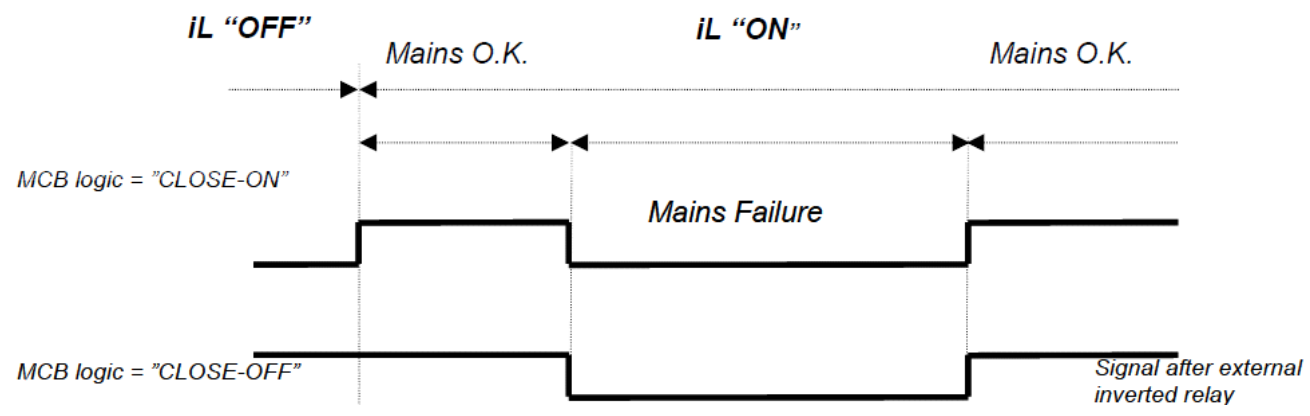

Fig10. Close-On / Close-Off

\section{Performance Evaluation}

The performance of the device shows that, the response of the system to over-voltage and undervoltage conditions was found to be satisfactory. Different load types and sizes were also connected to the output of the system; the over-current trip- point was quite satisfactory; and the displayed current and power factor values were found to confirm with the expected values for particular set of loads. The system's response to high and low frequency-supply was investigated by adjusting the speed of a generator which results in generator output frequency being varied. It was observed that the system responded to the preset frequency range.

Table1. Variation of Mains voltage against Generator voltage

\begin{tabular}{|l|l|l|l|l|l|}
\hline \multicolumn{6}{|l|}{ Mains Voltage (V) } \\
\hline $\mathbf{L}_{\mathbf{1}}$ & $\mathbf{L}_{\mathbf{2}}$ & $\mathbf{L}_{\mathbf{3}}$ & Phase selection & Generator Option & $\mathbf{V}_{\text {unreg }}(\mathbf{d . c})$ \\
\hline 310 & 300 & 280 & High Voltage & ON MODE & 22 \\
\hline 240 & 230 & 220 & $\mathrm{~L}_{1}$ & OFF MODE & 19 \\
\hline 230 & 230 & 210 & $\mathrm{~L}_{1}$ & OFF MODE & 18 \\
\hline 220 & 210 & 200 & $\mathrm{~L}_{1}$ & OFF MODE & 17 \\
\hline 210 & 200 & 190 & $\mathrm{~L}_{1}$ & OFF MODE & 16 \\
\hline
\end{tabular}


Ogundeji O.A. et al. "Integrated Power Monitoring and Control System"

\begin{tabular}{|l|l|l|l|l|l|}
\hline 200 & 190 & 180 & $\mathrm{~L}_{1}$ & OFF MODE & 15 \\
\hline 190 & 180 & 170 & $\mathrm{~L}_{1}$ & OFF MODE & 14 \\
\hline 180 & 170 & 160 & $\mathrm{~L}_{1}$ & OFF MODE & 13 \\
\hline 170 & 160 & 150 & $\mathrm{~L}_{1}$ & OFF MODE & 12 \\
\hline 160 & 150 & 140 & Low voltage & ON MODE & 11 \\
\hline 150 & 140 & 130 & Low voltage & ON MODE & 10 \\
\hline 140 & 130 & 120 & Low voltage & ON MODE & 9 \\
\hline
\end{tabular}

Table2. Reaction time for different over current levels

\begin{tabular}{|l|l|l|l|l|}
\hline \multicolumn{2}{|l|}{ Over current } & $101 \%$ & $110 \%$ \\
\hline $200 \%=2$ Inom del & $\leq 100 \%$ & No action & $20 \mathrm{~s}$ & $2 \mathrm{~s}$ \\
\hline \multirow{3}{*}{ Reaction time } & $\mathbf{0 . 2} \mathbf{s}$ & No action & $200 \mathrm{~s}$ & $20 \mathrm{~s}$ \\
\cline { 2 - 5 } & $\mathbf{2 ~ s}$ & No action & $\begin{array}{l}\text { No action } \\
\text { (time }>900 \mathrm{~s})\end{array}$ & $200 \mathrm{~s}$ \\
\cline { 2 - 5 } & $\mathbf{2 0 ~ s}$ & & \\
\hline
\end{tabular}

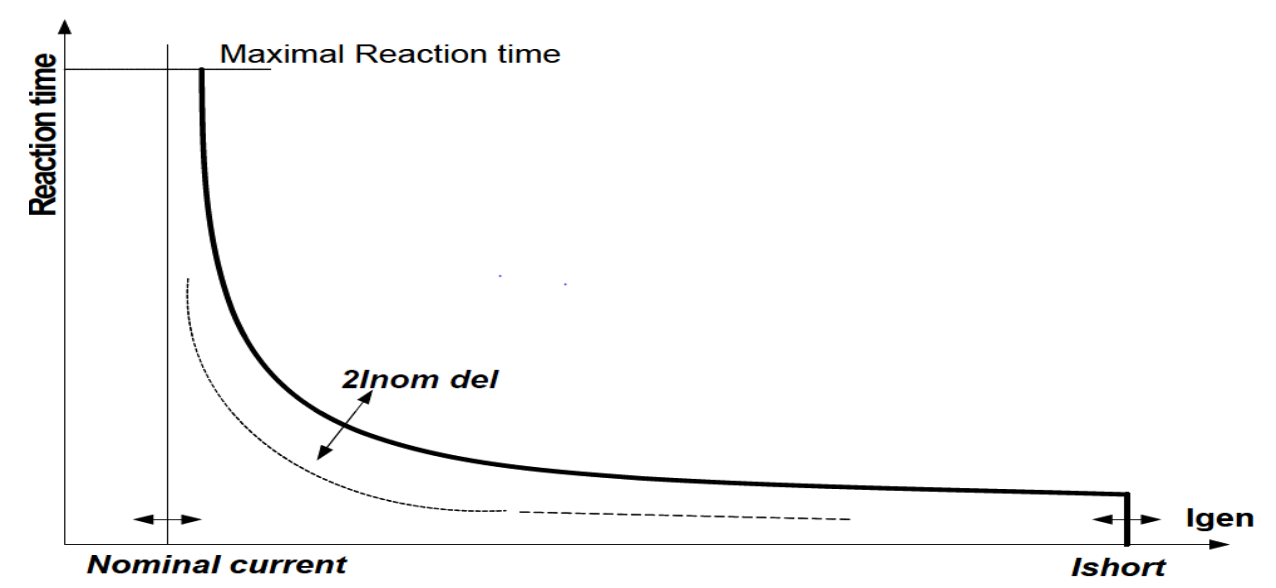

Fig11. Reaction- time graph

Table3. Setting value of Mains and Generator Parameter

\begin{tabular}{|c|c|c|c|}
\hline $\begin{array}{l}\text { GENERATOR } \\
\text { Frequency }\end{array}$ & $\begin{array}{l}\text { MAINS } \\
\text { Frequency }\end{array}$ & VOLTAGE (V) & CURRENT (I) \\
\hline $\begin{array}{l}\text { Step: } 0.1 \% \text { of } \\
\text { Nominal frequency }\end{array}$ & Maximum out of three is used. & $\begin{array}{l}\text { Maximum out of three is } \\
\text { used. }\end{array}$ & Step: 1 A \\
\hline $\begin{array}{l}\text { Range: } 0(\text { Gen }<\mathrm{f})- \\
200.0 \% \text { of Nominal } \\
\text { frequency }\end{array}$ & $\begin{array}{l}\text { Step: } 0.1 \% \text { of } \\
\text { frequency Range: } 50 \% \quad- \\
\text { 150.0(Mains }>\text { ) \%f }\end{array}$ & $\begin{array}{l}\text { Step: } 1 \% \text { of Nominal voltage } \\
\text { Range: } 50 \quad \text { (Mains <V) - } \\
150 \%\end{array}$ & Range: 1 - $10000 \mathrm{~A}$ \\
\hline $\begin{array}{l}\text { Step: } 0.1 \% \text { of } \\
\text { Nominal frequency }\end{array}$ & $\begin{array}{l}\text { Maximum out of three is used. } \\
\text { Step: } 0.1 \% \text { of Nominal } \\
\text { frequency }\end{array}$ & $\begin{array}{l}\text { Maximum out of three is } \\
\text { used. } \\
\text { Step: } 1 \% \text { of nominal voltage }\end{array}$ & Step: 1 A \\
\hline $\begin{array}{l}\text { Range: } 0.0-200 \\
(\text { Gen >f }) \% \text { of } \\
\text { Nominal frequency }\end{array}$ & 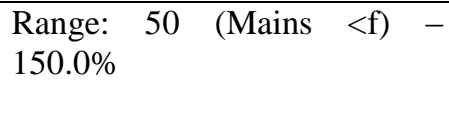 & $\begin{array}{l}\text { Range: } 50 \%-150 \text { (Mains } \\
>V \text { ) } \%\end{array}$ & $\begin{array}{l}\text { Range: } 1-5000 \mathrm{~A} \\
\text { / } 5 \mathrm{~A}\end{array}$ \\
\hline
\end{tabular}

\section{Calculation on setting Values}

\section{Voltage Values}

\section{High Voltage >}

$107 \%$ of nominal Voltage $(240)=107 * 240$

$$
\begin{aligned}
& 100 \\
& =256.8 \mathrm{~V}
\end{aligned}
$$

Low Voltage <

$75 \%$ of nominal Voltage $(240)=75 * 240$

100

$$
=180 \mathrm{~V}
$$


Frequency Values >

$120 \%$ of nominal frequency $(50)=120 * 50$

$$
\begin{aligned}
& 100 \\
& =60 \mathrm{~Hz}
\end{aligned}
$$

Frequency <

$90 \%$ of nominal frequency $(50)=90 * 50$

$$
=45 \mathrm{~Hz}
$$

Casing

Casing for electronic equipment is another important aspect of construction as it either attracts or discourages the consumer or end user. A good casing is not just a box but a container which should beautify the product and attract the targeted consumer of the product.

The material used in the casing of any electronic equipment must be carefully chosen as it has to satisfy basic safety requirements. Various materials like metal, wood, plastic, fibers e.t.c. could have been used. Other factors that we considered in making the choice of material were

- Cost

- Size

- Weight

- Risk of electric shock

After considering the factors written above, I decided to use metal in making the casing.

The dimension of the casing is $380 \mathrm{~mm} \times 160 \mathrm{~mm} \times 380 \mathrm{~mm}$ and it is shown in fig 4.4 below.

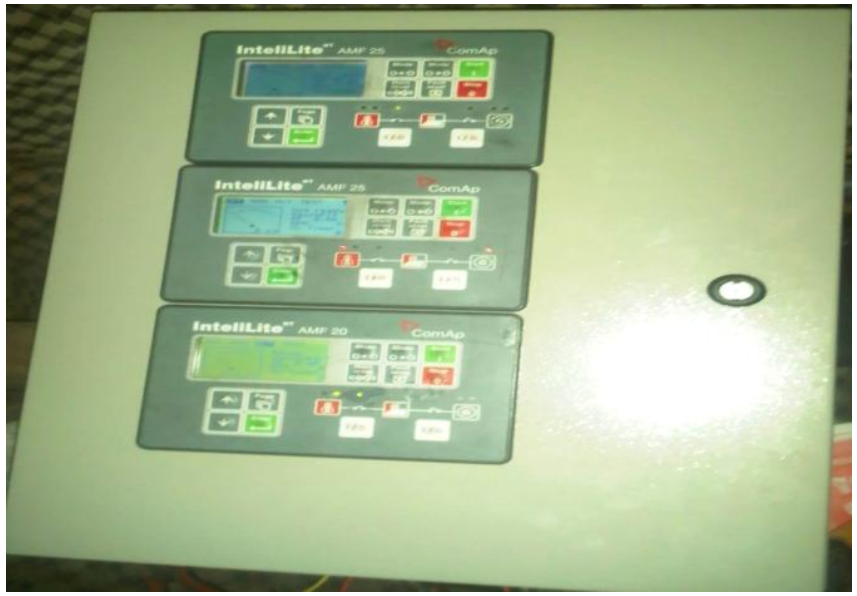

Fig12. Casing for the ACS

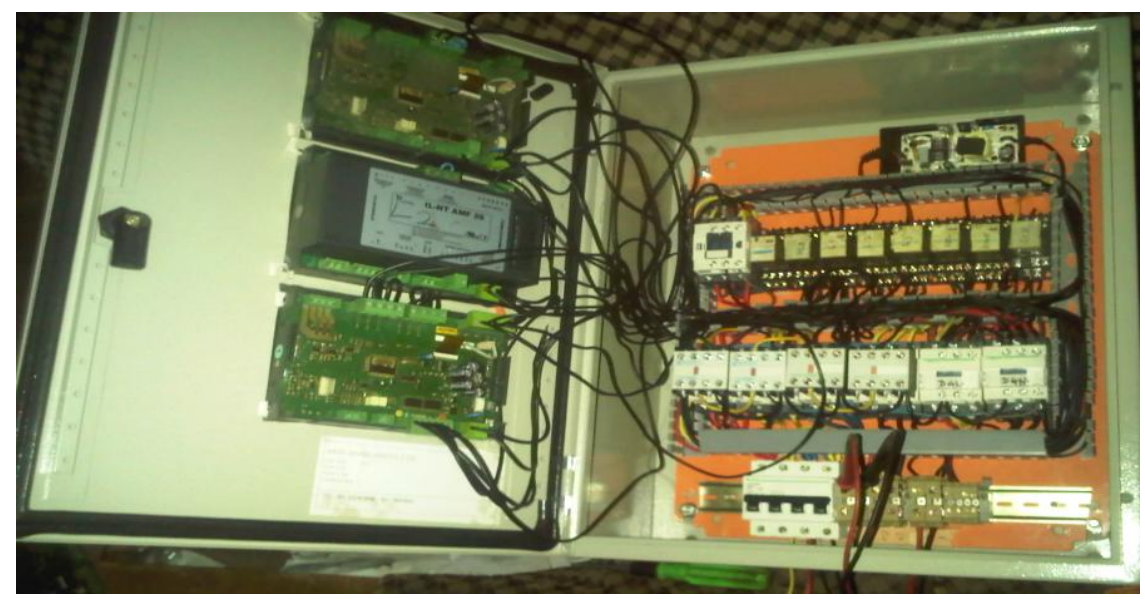

Fig13. Showing Internal structure of the System 


\section{Precaution}

Whenever automatic systems are used to start generator, it is necessary to put warning signs on the machine to indicate that it can start automatically.

Regular checks should be carried on the generator to ascertain battery voltage level, fuel level, oil level and pressure coolant in the radiator for water cooled engines.

\section{GCB Feedback}

Use this input for indication, whether the generator circuit breaker is open or closed.

If the feedback is not used, connect this input to the output GCB CLOSE/OPEN

\section{MCB Feedback}

This input indicates whether MCB is closed or opened.

\section{Emergency Stop}

If the input is opened, shut down is immediately activated. Input is inverted (normally closed) in default configuration.

In case of controller hardware or software fail, safe stop of the engine doesn't have to be ensured. To back-up the Emergency stop function it is recommended to connect separate circuit for disconnection of Fuel solenoid and Starter signals.

\section{Access Lock}

If the input is closed, no setpoints can be adjusted from controller front panel and gen-set mode (OFFMAN-AUT-TEST) cannot be changed.

Access lock does not protect setpoints and mode changing from LiteEdit. To avoid unqualified changes the selected setpoints can be password protected.

\section{Test on Load}

When input is closed, the controller automatically transfers load from the mains to the generator set. Set point AutoMainsFail: Load is automatically transferred back to the mains when any generator set shut down protection activates.

\section{Start Button}

Binary input has the same function as Start button on the InteliLite front panel. It is active in MAN mode only.

\section{Stop Button}

Binary input has the same function as Stop button on the InteliLite front panel. It is active in MAN mode only.

\section{Fault Reset Button}

Binary input has the same function as Fault reset button on the InteliLite front panel.

\section{Mains Fail Block}

If the input is closed, the automatic start of the gen-set at Mains failure is blocked. In case of running gen-set the GCB is opened, gen-set goes to Cooling procedure and stops. The input simulates healthy Mains.

\section{Basic Settings}

\section{Generator-Set Name}

User defined name, used for InteliLite identification at remote phone or mobile connection. Gen-set name is max 14 characters long and have to be entered using LiteEdit software.

\section{Nominal Power $[\mathrm{kW}]$}

Nominal power of the generator

Step: $\quad 1 \mathrm{~kW}$

Range: $\quad 1-32000 \mathrm{~kW}$

27 International Journal of Emerging Engineering Research and Technology V5 • I3 • March 2017 


\section{Nominal current [ A ]}

It is current limit for generator *IDMT over current and short current protection and means maximal continuous generator current. See Generator protections

Nominal current can be different from generator rated current value.

Step: $\quad 1 \mathrm{~A}$

Range: $\quad 1-10000 \mathrm{~A}$

\section{Nominal Voltage [V]}

Nominal generator voltage (phase to neutral)

Step: $\quad 1 \mathrm{~V}$

Range: $\quad 80-20000 \mathrm{~V}$

\section{Nominal Frequency [Hz]}

Nominal generator frequency (usually 50 or $60 \mathrm{~Hz}$ )

Step:

$1 \mathrm{~Hz}$

Range:

$45-65 \mathrm{~Hz}$

\section{Gear Teeth}

Number of teeth on the engine gear for the pick-up.

Set to zero, if no pick-up is used. Engine speed is counted from the generator frequency.

Step: $\quad 1$

Range: $\quad 0-500$

Generator frequency can be used only when generator voltage (min $5 \mathrm{~V}$ ) is present before reaching ofthe firing speed (Starting RPM) after start.

\section{[RPM]}

\section{Nominal RPM}

Nominal Engine speed.

Step: $\quad$ 1RPM

Range: $\quad 100-4000$ RPM

\section{Starting RPM [\%]}

"Firing" speed when IL controller stops cranking (starter goes OFF).

Step: $\quad 1 \%$ of nominal RPM

Range: $\quad 5-50 \%$

\section{Prestart Time}

Time of closing of the PRE-START output prior to the engine start.

Set to zero if you want to leave the output PRE-START open.

Step: 1 s

Range: $\quad 0-600 \mathrm{~s}$

\section{Max Crank Time [s]}

Maximum time limit of cranking.

Step: $\quad 1 \mathrm{~s}$

Range: $\quad 1-60 \mathrm{~s}$ 


\section{Crank Fail Pause [s]}

Pause between crank attempts.

Step: $\quad 1 \mathrm{~s}$

Range: $\quad 5-60 s$

\section{Crank Attempts [-]}

Max number of crank attempts.

Step: $\quad 1$

Range: $\quad 1-10$

\section{Idle Time [s]}

Idle time delay starts when RPM exceeds Start RPM. Start fail is detected when during Idle state RPM decreases.

During the Idle time timer running the binary output IDLE/NOMINAL is opened, when it elapses the IDLE/NOMINAL output closes. Binary output IDLE/NOMINAL opens during Cooling period again.

Step: $\quad 1 \mathrm{~s}$

Range: $\quad 0-600 \mathrm{~s}$

\section{Problems Encountered during Device Development}

The only major problems encountered during the development of this device were:

The critical components; the microcontroller, PIC18F4431 and the FETs input Op-Amps were very scarce and that made us to improvised using (AMF) module to accomplish our goal.

\section{CONCLUSION AND RECOMMENDATION}

\section{Conclusion}

The various tests carried out and the results obtained demonstrate that the integrated power monitoring and Control System achieved its design and construction aims. The system worked according to specifications, and quite satisfactory. The system is relatively affordable and reliable. It is easy to operate, and it provides a highly efficient power supply switches in response to Remote "POWER-OFF" Command or in the event of abnormal line parameters.

\section{Recommendation}

The following recommendations are necessary in order to implement preventive maintenance, improve on the efficiency, increased adaptability, and ease of integration into existing power system networks. Future work on this device should incorporate the following features.

- An RS232 serial communication port can be integrated into the device, this will enable the device's connection to computer systems and / or networks.

- The meter may be upgrade to smart meter, which is an advanced meter that identifies consumption in more details than a conventional meter; and communicates that information via some network back to the local utility for monitoring and billing purpose. The traditional electrical meter only measure total consumption and as such, provide no information of when the energy was connected, while smart meter provide an economical way of measuring this information, allowing matching of consumption with generation.

- Charging circuit for the battery can also be incorporated to charge the battery in order to provide continuous power supply to the modules in case there is there is constant supply from the mains supply and the generator set is not engaged.

- It also recommended that improvement should be made on this project to make it useful for commercial and industrial energy consumers. 


\section{REFERENCES}

[1] Elektor B.V., Build Your Own Electronic Test Instruments, Singapore: Tech Publications PTE Limited, (1995).

[2] Jonathan GanaKolo, Design and Construction of an Automatic Power, Changeover Switch, (2007).

[3] Lionel W., Electronic \& Electrical Engineering, Principle \& Practice, Second Edition, United Kingdom, Macmillan, (1998).

[4] Millman H., Integrated Electronics, Tokyo (Japan): McGraw-Hill, (1972).

[5] M.S. Ahmed, A.S. Mohammed and O.B. Agusiobo, Development of a Single Phase Automatic Change-Over Switch Department of Electrical and Computer Engineering, Federal University of Technology Minna, Nigeria, (2006).

[6] Owen, B., Beginner's Guide to Electronics $4^{\text {th }}$ Edition. Newness Technical Book, New York, USA: McGraw-Hill Companies Inc., (1995).

[7] Paul H. \& Winfield H., The art of electronics, Second Edition, United Kingdom: Cambridge University Press, (1995).

[8] Rocks G. \&Mazu, G., Electrical motor controls. New-York, USA: American Technical Publishing, (1993).

[9] Theraja, B.L. \&Theraja, A.K.,Electrical Technology, $21^{\text {st }}$ Edition Ram Nagar New Delhi, India: S. Chand and Company Ltd., (2002).

Websites: http://en.wikipedial.org/wiki, November, 2015. 2.30pm

http://www.alldatasheet.comNovember, 2015. 2.00pm

http:www.microhip.comNovember, 2015. 1.30pm 